\title{
Nonhematopoietic Nrf2 dominantly impedes adult progression of sickle cell anemia in mice
}

\author{
Samit Ghosh, ${ }^{1,2}$ Chibueze A. Ihunnah, ${ }^{2}$ Rimi Hazra, ${ }^{2}$ Aisha L. Walker, ${ }^{2}$ Jason M. Hansen, ${ }^{3}$ \\ David R. Archer, ${ }^{4}$ Amma T. Owusu-Ansah, ${ }^{1,2}$ and Solomon F. Ofori-Acquah ${ }^{1,2}$ \\ 'Division of Hematology/Oncology, and ${ }^{2}$ Center for Translational and International Hematology, Vascular Medicine \\ Institute, Department of Medicine, School of Medicine, University of Pittsburgh, Pittsburgh, Pennsylvania, USA. \\ ${ }^{3}$ Department of Physiology and Developmental Biology, Brigham Young University, Provo, Utah, USA \\ ${ }^{4}$ Department of Pediatrics, Emory University School of Medicine, Atlanta, Georgia, USA.
}

\begin{abstract}
The prevention of organ damage and early death in young adults is a major clinical concern in sickle cell disease (SCD). However, mechanisms that control adult progression of SCD during the transition from adolescence are poorly defined with no cognate prophylaxis. Here, we demonstrate in a longitudinal cohort of homozygous SCD (SS) mice a link between intravascular hemolysis, vascular inflammation, lung injury, and early death. Prophylactic Nrf2 activation in young SS mice stabilized intravascular hemolysis, reversed vascular inflammation, and attenuated lung edema in adulthood. Enhanced Nrf2 activation in endothelial cells in vitro concurred with the dramatic effect on vascular inflammation in the mice. BM chimeric SS mice lacking Nrf2 expression in nonhematopoietic tissues were created to dissect the role of nonerythroid Nrf2 in SCD progression. The SS chimeras developed severe intravascular hemolysis despite having erythroid Nrf2. In addition, they developed premature vascular inflammation and pulmonary edema and died younger than donor littermates with intact nonhematopoietic Nrf2. Our results reveal a dominant protective role for nonhematopoietic Nrf2 against tissue damage in both erythroid and nonerythroid tissues in SCD. Furthermore, we show that prophylactic augmentation of Nrf2-coordinated cytoprotection effectively impedes onset of the severe adult phenotype of SCD in mice.
\end{abstract}

Conflict of interest: The authors have declared that no conflict of interest exists.

Submitted: February 2, 2015 Accepted: February 26, 2016 Published: April 7, 2016

Reference information: JCI Insight. 2016;1(4):e81090. doi:10.1172/jici.nsight.81090.

\section{Introduction}

Sickle cell disease (SCD) is a monogenic blood disorder caused by a single point mutation in the $\beta$-globin gene. It is characterized by multisystem morbidity and early mortality (1). The survival of children with SCD has improved dramatically over the last 30 years in the USA and in Europe, reaching up to $99 \%$ at $18-20$ years in multiple birth cohorts (2-4). This is due largely to effective prophylactic management of infection (5) in infants identified by newborn screening programs (6-8). In countries where these public health services are missing, childhood mortality is approximately $95 \%$ by age 5 (9-11). However, SCD patients who are 20 years and older in the West continue to die at an alarming rate $(1,8,12)$. It is widely believed that poor access to health care and other systemic social hurdles drive the poor outcome in adult SCD patients, particularly during the transition from pediatric to adult care $(2,3,13)$. Hitherto, the potential role the pathobiology of SCD may play in this problematic transition has not been defined.

Although intravascular hemolysis is intrinsic to SCD, its specific role in the rapid disease deterioration seen in young adults has not previously been determined. The intensity of intravascular hemolysis varies in different patients (14). Nonetheless, the plasma of virtually all SCD patients contains excess cell-free hemoglobin $(\mathrm{Hb})$ and low to undetectable levels of the $\mathrm{Hb}$ scavenger haptoglobin (15). Oxidation of free $\mathrm{Hb}$ generates hydroxyl and lipid peroxyl radicals, and free heme generates a potent inflammatory agent and oxidant. We proposed previously that, together with other erythroid damage-associated molecular pattern (eDAMP) molecules, free heme may drive sterile inflammation to promote the vascular inflammation and pulmonary dysfunction seen with aging in SCD (16).

Nuclear factor erythroid-2-related factor 2 (Nrf2), a ubiquitously expressed basic leucine zipper (b-Zip) transcription factor coordinates the expression of approximately 200 antioxidant response (ARE) genes, 
A

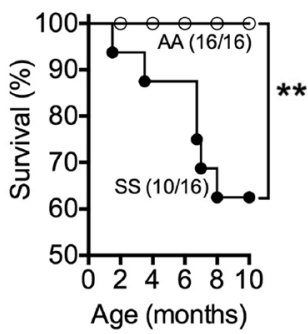

B

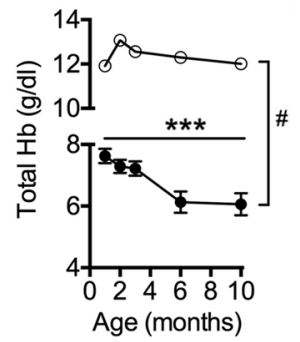

C

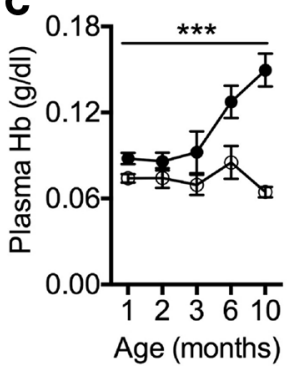

D

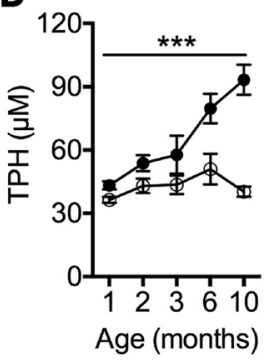

E

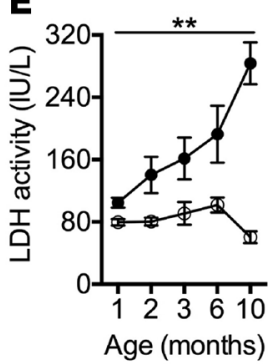

- SS

OAA

Figure 1. Severity of hemolytic anemia and mortality rate increases with aging in sickle mice. (A) Mortality in a cohort of transgenic sickle (SS) and control (AA) mice during an observational period of 10 months. ${ }^{*} P<0.01$, measured by Mantel-Cox test. (B) Total hemoglobin (total Hb) concentration declined sharply during the adult maturation phase in the SS but not in the AA mice $(n=10-16)$. $P<0.001$ in total Hb between AA and SS at all ages studied, unpaired $t$ test. (C-E) Serial measurement of the concentrations of cell-free hemoglobin in the plasma (plasma Hb), total plasma heme (TPH), and activity of plasma lactate dehydrogenase (LDH activity) documenting increasing severity of intravascular hemolysis in aging SS mice ( $n=9$ ). ${ }^{* *} P<0.01$ and ${ }^{* *} P<0.001$, measured by ANOVA within SS mice at different ages.

including $\mathrm{NAD}(\mathrm{P}) \mathrm{H}$ :quinone oxidoreductase 1 (NQO1) and both heavy $(\mathrm{FTH})$ and light $(\mathrm{FTL})$ chain genes of ferritin, during periods of oxidative stress $(17,18)$. Nrf2 deficiency causes a mild hemolytic anemia in mice (19), and targeted deletion of one of its target peroxiredoxins causes a similar phenotype in mice (20). Sickle erythrocytes have reduced levels of many Nrf2-regulated gene products - including superoxide dismutase, catalase, glutathione peroxidase $1(21,22)$ - and reduced glutathione $(23,24)$. These deficiencies reflect impairment of erythroid Nrf2 activity in SCD that increases oxidative stress and reactive oxygen species in erythrocytes. Relatively lower erythroid Nrf2 expression is found in SCD patients with the most severe anemia (25). Collectively, these observations indicate that SCD is associated with defects in erythroid Nrf2-related activities, which promote intravascular hemolysis. Nrf2 expression in nonerythroid tissues may therefore play a dominant role in limiting progression of SCD.

\section{Results}

Transgenic sickle mice recapitulate the adult progression of SCD in humans. The sharp rise in mortality rate among adolescents and young adults who have SCD is a major clinical concern. To investigate this phenomenon, we first assessed whether the murine SCD model recapitulates this pattern of death. A survival study of a large cohort of C57BL/6J mice focused on life-stage equivalencies indicates mice aged 3 months are comparable to humans aged 20 years, with respect to maturation (26).

Here, we conducted a 10-month longitudinal observational study, beginning at 1 month, of a random cohort of transgenic mice with homozygous SCD of both sexes (female $n=8$, male $n=8$ ) and control mice, also of both sexes, expressing normal adult human $\mathrm{Hb}(\mathrm{AA} ; n=16)$. During this period $6(37.5 \%)$ of the homozygous SCD cohort (SS) mice died, but there were no deaths in the AA mice (log-rank Mantel Cox test, $P<0.01$ ) (Figure 1A). Virtually all the deaths (i.e., 83\%) occurred in adult SS mice aged 3-8 months. All mice were bled only once during this period (at age 6 months), which suggests that phlebotomy was not a major factor in the reduced survival in the SS mice. Among the SS mice that died, 4 were males and 2 were females.

The higher death rate in males reflects the sex bias seen in humans with SCD (1). These observations indicate that, like humans, transgenic mice with SCD also experience a sharp rise in mortality during adult maturation and are therefore a good model to investigate the mechanisms that drive age-related progression of SCD.

Anemia is a hallmark of both aging and SCD; therefore, we examined whether this event contributes to the poor prognosis in maturing SS mice. Compared with AA mice, total $\mathrm{Hb}$ was lower in the SS mice, regardless of age $(P<0.001)$. Total $\mathrm{Hb}$ in the SS mice dropped sharply and significantly by approximately $20 \%$ from age $3-6$ months $(P=0.02)$, while the mean value in the AA mice remained stable during this period (Figure 1B).

Worsening anemia in the SS mice was corroborated by a significant age-associated increase in the concentrations of multiple plasma markers of intravascular hemolysis. They included cell-free $\mathrm{Hb}$ (Plasma $\mathrm{Hb}$ ) and heme measured as total plasma heme (TPH) (Figure 1, C and D), as well as in the activity of plasma lactate dehydrogenase $(\mathrm{LDH})$ (Figure $1 \mathrm{E})$. The mean $\mathrm{TPH}$ rose significantly at 2 month $(53.8 \pm 3.8$ 

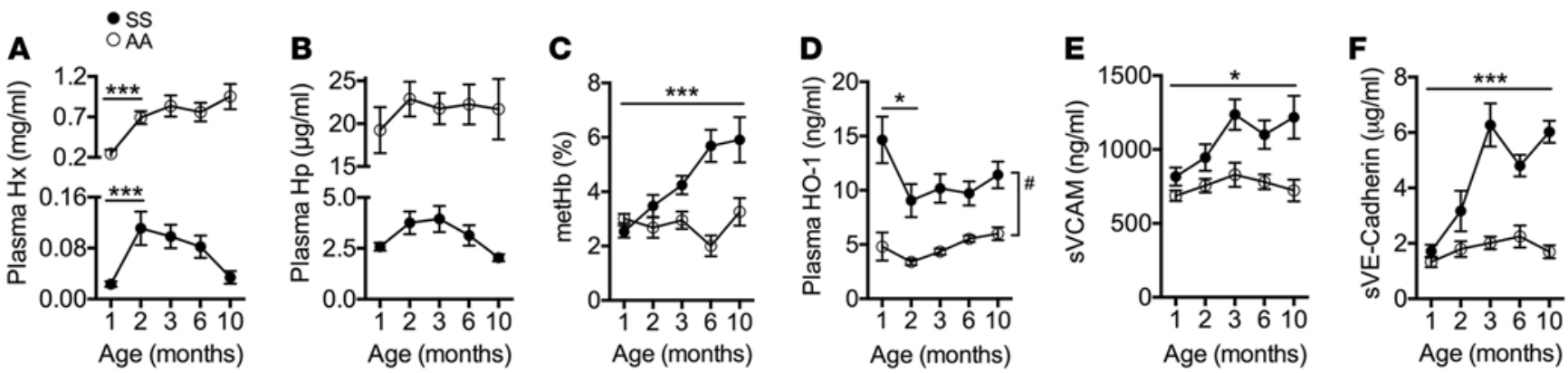

G

Age (months)

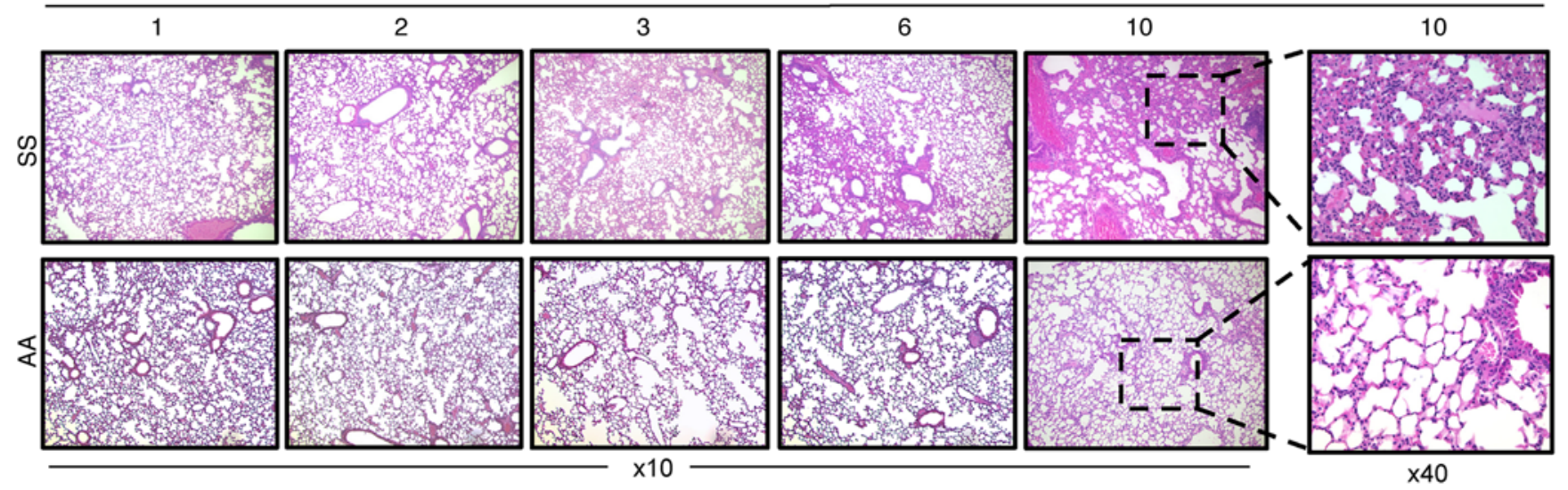

Figure 2. Hemolytic stress, vascular inflammation, and lung injury deteriorate with aging in sickle mice. (A) Extremely low hemopexin level in 1-monthold transgenic sickle (SS) mice $(n=8-14)$ followed by declining values thereafter. By contrast plasma hemopexin (plasma Hx) level rises steadily in the maturing control (AA) mice ( $n=14)$ and plateaus at a high value in adulthood ( ${ }^{* *} P<0.001$ using $t$ test between 1 and 2 months). (B) Developmentally stable plasma haptoglobin (plasma Hp) level in both SS and AA mice $(n=8-14)$. (C) Progressive increases in percent methemoglobin (metHb) in SS but not in AA mice. (D) Plasma heme oxygense-1 (HO-1) level in 1-month SS mice is markedly high and drops to a stable value thereafter. The HO-1 level in AA mice is lower than in SS at all stages of maturation $(n=10)$. ${ }^{*} P<0.05$ comparing H0-1 level in SS between 1 and 2 months using $t$ test; ${ }^{\#} P<0.001$ showing difference in plasma $\mathrm{HO}-1$ concentration of AA and SS mice at different ages, unpaired $t$ test. (E) The concentration of soluble vascular cell adhesion molecule (sVCAM-1), a marker of endothelial injury in plasma, increases steadily in the SS but not in the AA mice with aging $(n=6-9)$. (F) Concentration of soluble vascular endothelial cadherin (sVE-cadherin) is also similar at 1 month in both groups of mice but rises steadily in the SS mice and reaches a significantly elevated level at 3 months $(n=6) .{ }^{*} P<0.05$ and ${ }^{* *} P<0.001$, indicating statistical differences (ANOVA) between SS mice 1-10 month of age. (G) Representative $\mathrm{H} \& \mathrm{E}$-stained lung tissue sections of SS and AA mice at 1-10 months of age ( $\times 10)$. Higher magnification ( $\times 40)$ of the 10-month-old lung section for indicated area features alveolar wall thickening and edema in SS mice. Original magnification $\times 100$ and $\times 400$.

$\mu \mathrm{M})$ compared with the value at 1 month $(43.3 \pm 1.9 \mu \mathrm{M})(P=0.006)$. The LDH activity at 3 months was significantly higher than at 1 month $(161.5 \pm 26.94 \mathrm{IU} / 1$ versus $104.7 \pm 6.44 \mathrm{IU} / 1, P=0.022)$, while the plasma cell-free $\mathrm{Hb}$ concentration increased significantly during the 3-6 month adult maturation period $(0.09 \pm 0.1$ versus $0.18 \pm 0.01 ; P=0.016)$. Collectively, these data identified exacerbation of intravascular hemolysis, which was evident as early as 2 months, as a contributor to the age-related deteriorating anemia in the SS mice.

Impaired heme scavenging in SCD deteriorates with adult maturation in mice. Hemopexin protects the vascular wall against the deleterious effects of intravascular hemolysis by removing excess heme from the circulation for degradation in the liver (16). Plasma hemopexin levels at 1 month were lower in both AA and SS mice compared with values that were attained in later development. However, the mean value in the SS mice was 10 -fold lower. The mean values increased by approximately 4 -fold in both groups at 2 months, followed by an additional $20 \%$ increase in the AA mice and stabilization thereafter with a mean value of $0.8 \mathrm{mg} / \mathrm{ml}$ in the adult stage. The hemopexin rise in the SS mice stalled at 2 months and began a sharp, steady decline throughout adult maturation (Figure 2A). There was no appreciable change in the plasma concentration of haptoglobin in either group with aging (Figure $2 \mathrm{~B}$ ). Whole blood co-oximetry revealed a progressive rise in percent methemoglobin (metHb) in the SS mice. The mean percent metHb at 3 months was significantly higher than the initial mean value at 1 month $(4.24 \% \pm 0.34 \%$ versus $2.53 \% \pm 0.22 \%, P=0.0003)$, and it 
A

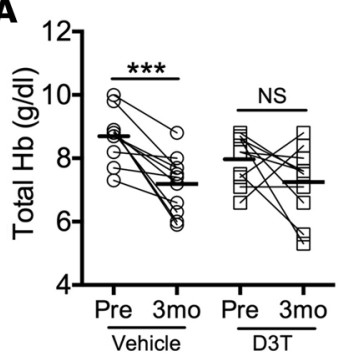

E

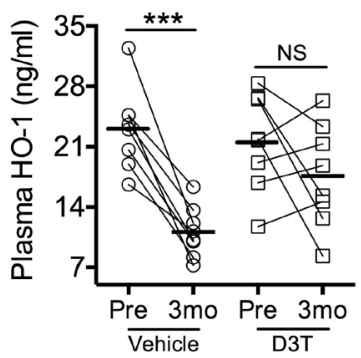

B

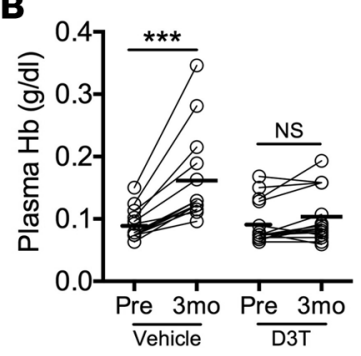

F

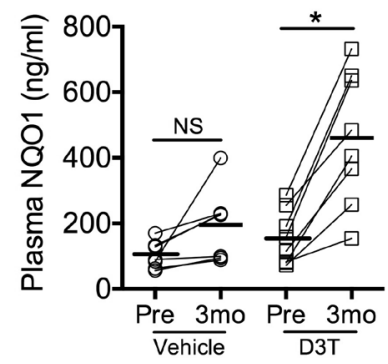

C

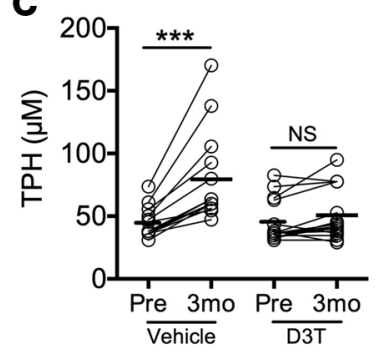

G

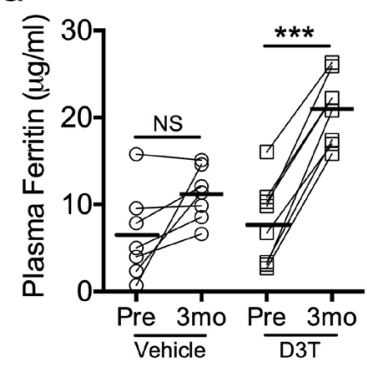

D

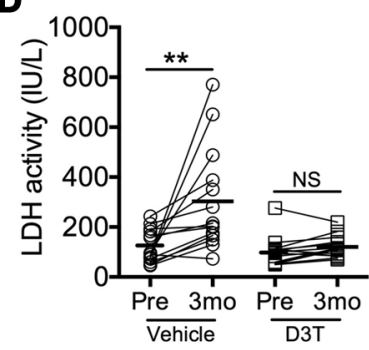

Figure 3. Nrf2 activation stabilizes the severity of hemolytic anemia in sickle mice. (A-D) Paired values of the concentrations of total hemoglobin (total $\mathrm{Hb}$ ) (A), cell-free plasma hemoglobin (B), plasma heme (TPH) (C), and plasma LDH activity (D) for individual SS mice at the time of initiating treatment with D3T (Pre) and 3 months (3mo) after the treatment $(n=10-11)$. Note D3T blocked the age-dependent decrease in total hemoglobin in the SS mice, which is reflected by a corresponding blockade of increased concentration of the 3 intravascular hemolysis markers. (E-C) Protein concentrations of multiple Nrf2-regulated target genes determined by ELISA. D3T stabilized the decline in $\mathrm{HO}-1$ expression with aging in the SS mice and significantly induced the expression of NQO-1 and ferritin $(n=7-8)$. Statistical analysis was performed using paired $t$ test between "Pre" and "3mo" within vehicle- or D3T-treated group. ${ }^{*} P<0.05,{ }^{* *} P<0.01$, and ${ }^{* * *} P<0.001$. D3T, 3H-1, 2-dithiole-3-thione; LDH, lactate dehydrogenase; SS, transgenic sickle; Nrf2, nuclear factor erythroid-2- related factor 2; HO-1, heme oxygenase-1; NQ01, NAD(P)H:quinone oxidoreductase 1.

increased further, reaching an approximately 3-fold higher value at 6 months (Figure 2C). Enhanced expression of heme oxygenase-1 (HO-1) is thought to lessen oxidative stress in SCD by degrading heme to yield multiple byproducts with antioxidant and cyto-protective properties. Consistent with this idea, the HO-1 level in the SS plasma was 2- to 3 -fold higher than in the AA mice $(P<0.001)$. Interestingly, the plasma HO-1 level in the SS mice was relatively higher at 1 month; the mean value dropped significantly at 2 months and remained stable thereafter $(P<0.05)$ (Figure 2D). To examine further the imbalance in oxidative stress and the antioxidant response in the SS mice, we assessed levels of plasma biothiols, namely cysteine/cystine (Cys/CySS) and glutathione/glutathione disulfide (GSH/GSSG) using HPLC, as described previously (27). Both of these redox couples were more oxidized in the SS mice, and the Cys/CySS couple became more oxidized during the 3-6 month adult transition in the SS mice but not in the AA mice (Supplemental Figure 1, A and B; supplemental material available online with this article; doi:10.1172/jci.insight.81090DS1). Together, these data show that impaired scavenging of heme occurs early in SCD and may promote oxidative damage at a relatively young age that deteriorates with adult maturation.

Transgenic sickle mice develop progressive endothelial injury and lung damage. The concentration of soluble vascular cell adhesion molecule (sVCAM-1) in the plasma is a well-known marker of endothelial injury and inflammation. As reported elsewhere for patients (28), plasma SVCAM-1 was significantly elevated in SS mice of all ages compared with age-matched AA controls. The plasma sVCAM-1 level in the SS mice, but not in the AA mice, increased significantly from 1-10 months, indicative of an age-related progression of vascular inflammation in the SS mice $(P<0.05)$ (Figure $2 \mathrm{E})$. To further explore the endothelial injury in SS mice, we focused on vascular endothelial cadherin (VE-cadherin), which tethers endothelial cells together to control fluid extravasation into interstitial tissue compartments. To the best of our knowledge, VE-cadherin has never been studied in SCD. At 1 month, the mean plasma VE-cadherin was similar in SS $(1.72 \pm 0.23 \mu \mathrm{g} / \mathrm{ml})$ and AA $(1.33 \pm 0.18 \mu \mathrm{g} / \mathrm{ml})$ mice. This value increased 3.5 -fold by 3 months and remained significantly elevated $(P<0.001)$ throughout the adult maturation in the SS mice, while the relatively lower value in the AA mice remained unchanged (Figure $2 \mathrm{~F}$ ).

Intravascular hemolysis is commonly associated with chronic lung damage in SCD patients. Thus, at the end of the 10-month observational period, we performed histology to assess for lung damage and 
A

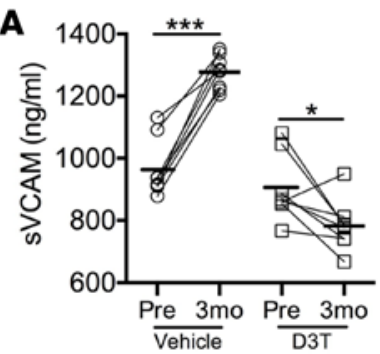

B

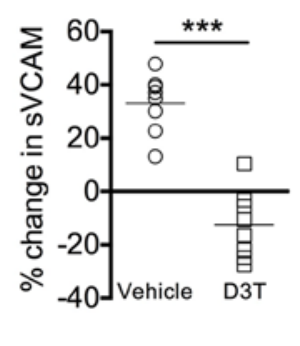

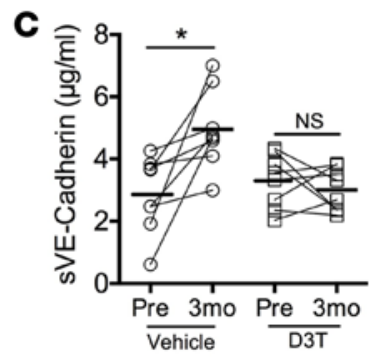

D

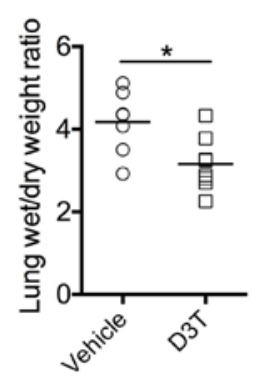

E

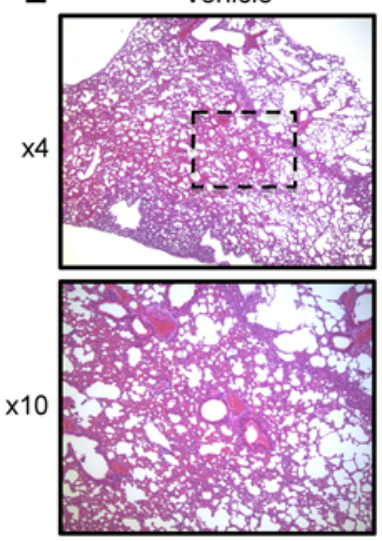

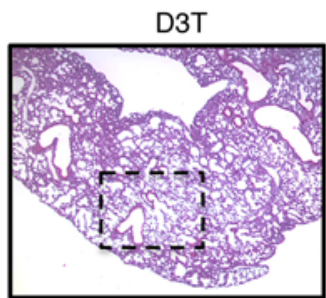

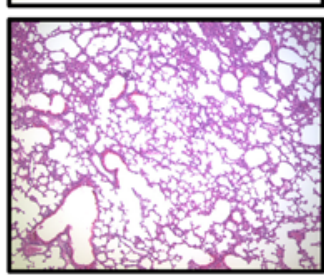

$\mathbf{F}$

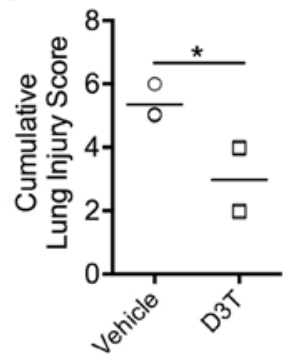

Figure 4. Nrf2 activation reverses endothelial inflammation and impedes lung damage in sickle mice. (A and $\mathbf{B}$ ) Oral gavage with D3T reduced the plasma concentration of SVCAM while treatment with DMSO did not change the progressive increase in this endothelial injury marker ( $n=7-8)$. (C) Protein concentration of sVE-cadehrin in plasma determined by ELISA. Data shows progressive increase with aging in the vehicle, which is halted by D3T. (D) Assessment of lung edema by wet/dry weight ratio indicate D3T treatment attenuated vascular leakage in the lungs of SS mice ( $n=7-8$ ). (E) Representative H\&E staining of lung tissue sections of SS mice treated with D3T or vehicle $(n=3-4)$ for 5 months. Images were acquired at original magnification of $\times 40$ (labeled $\times 4$ ) and then at an original higher magnification of $\times 100$ (labeled $\times 10$ ) in the highlighted region. (F) Cumulative histological injury score derived from edema, congestion, and alveolar wall thickness from H\&E-stained lung sections $(n=3-4){ }^{*} P<0.05$ and ${ }^{* * *} P<0.001$ (paired $t$ test while comparing "pre" and "3mo" within vehicle or D3T group; unpaired $t$ test while comparing vehicle versus D3T group). Nrf2, nuclear factor erythroid-2related factor 2; D3T, 3H-1, 2-dithiole-3-thione; SVCAM, soluble vascular cell adhesion molecule; sVE-cadherin, soluble vascular endothelial cadherin; SS, transgenic sickle; "pre", prior to treatment; "3mo", after 3 months of treatment.

discovered that the SS mice had severe congestion, edema, and alveolar wall thickening, while a majority of the AA mice had relatively normal lung histology (Supplemental Figure 2, A and B). To confirm these findings, we studied a random selection of SS and AA mice aged 1-10 months ( $n=3$ each). The concentration of multiple markers of intravascular hemolysis was significantly higher in older SS mice in this cross sectional cohort, in agreement with the data from our longitudinal cohort (Supplemental Figure 3, A-C). There was no tissue damage in the lungs of 1- and 2-month-old SS mice, while the lungs of 3-month-old animals had a few areas of mild to moderate congestion. Tissue injury was more severe in 6-month-old SS mice, and in agreement with the results from the longitudinal cohort, the damage to the lung was more severe and more widespread in 10-month-old SS mice (Figure 2G). Together, these data link worsening intravascular hemolysis and oxidative stress to the release of VE-cadherin, the major component of the endothelial wall into the circulation, and progressive lung damage in SS mice with aging.

Nrf2 activation stabilizes severity of hemolytic anemia in transgenic sickle mice. Nrf2 regulates the expression of several genes that protect against the effects of intravascular hemolysis. We tested the idea that Nrf2 activation in young sickle mice would slow down disease progression with aging. Newly weaned SS mice approximately 1 month old were randomized to receive 3H-1, 2-dithiole-3-thione (D3T) (29), or a DMSO vehicle by oral gavage $(0.5 \mathrm{mmol} / \mathrm{kg}, 3 \times /$ week $)$. After 3 months, D3T stabilized the concentration of $\mathrm{Hb}$, while the $\mathrm{Hb}$ level declined significantly in the vehicle group, in agreement with our earlier results in the longitudinal mouse cohort (Figure 3A). The stability in $\mathrm{Hb}$ was reflected by comparable stabilization of the plasma concentrations of cell-free $\mathrm{Hb}(P<0.001)$, heme (TPH; $P<0.001)$, and LDH (Figure 3, B-D). After 3 months of treatment, the D3T group had virtually no change in the intravascular hemolysis markers, whereas each of the 3 markers increased substantially during the same period in the DMSO group 
A

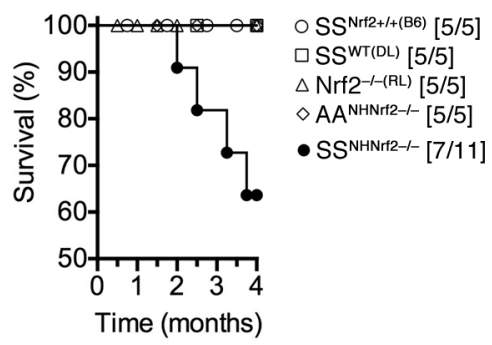

B

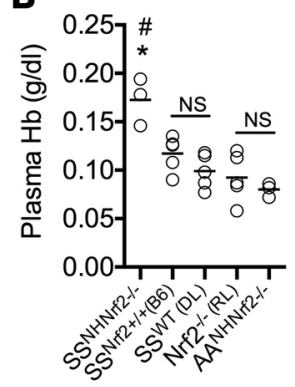

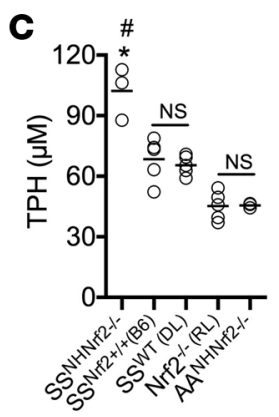

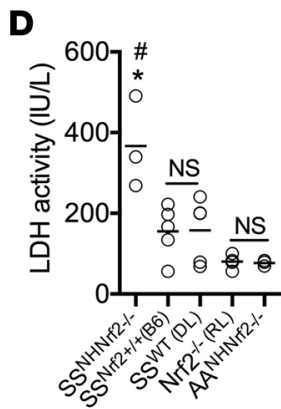

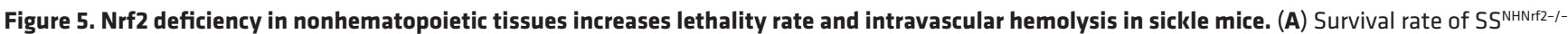
chimeras and various control mice from the time of engraftment: SSWT(DL), littermates of the SS mice that were used as BM donors; Nrf2-I-(RL), littermates of $\mathrm{Nrf2}^{-/-}$mice that received SS or AA BM; SS ${ }^{\mathrm{Nr} 2+/+(\mathrm{B} 6)}$, congenic $\mathrm{Nrf2}^{+/+}[57 \mathrm{BL} / 6]$ mice transplanted with SS BM; and $\mathrm{AA}^{\mathrm{NHNr}}$, transplanted with AA BM. (B-D) Plasma concentration of multiple markers of intravascular hemolysis (plasma Hb, TPH, and LDH) indicates a more severe

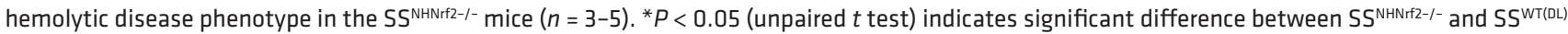

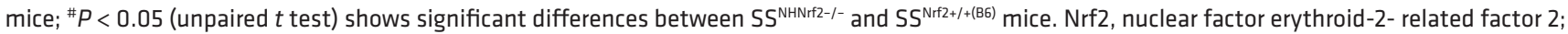
SS, transgenic sickle; AA, control mice; SS $\mathrm{NHNrf2--}^{-}, \mathrm{Nrf2}^{-/-}$mice that received bone marrow from SS mice; Hb, Hemoglobin; TPH, total plasma heme; LDH, lactate dehydrogenase.

(Supplemental Figure 4, A-C). We obtained similar stabilizing effects on intravascular hemolysis when we started D3T treatment at 2 months (data not shown). The total wbc count increased significantly after 3 months of D3T, presumably because of the long treatment duration (Supplemental Figure 5, A-D). However, this data suggests that the stabilization of intravascular hemolysis in the SS mice was not due to lessening of systemic inflammation. The mean reticulocyte count increased by $5 \%$ in the D3T group $(57.5 \% \pm$ $2.5 \%$ versus $62.5 \% \pm 2.0 \%$ ) compared with $<1 \%$ in the vehicle $(55.8 \% \pm 1.4 \%$ versus $56.5 \% \pm 2.7 \%)$ after 3 months of treatment; however, the changes were not significantly different. We determined previously that HO-1 expression declines sharply in the second month of life in SS mice (Figure 2D). The mean HO-1 level in the D3T group remained stable for 3 months, while it declined significantly during the same period in the DMSO group, in agreement with our longitudinal data (Figure 3E). Markedly elevated levels of NQO1 and ferritin provided additional evidence of Nrf2 activation by D3T (Figure 3, F and G). Together, these data indicate prophylaxis with Nrf2 activators can arrest age-related deterioration of hemolytic anemia in SCD and potentially slow the deleterious effects of free heme on the vasculature.

Nrf2 activation impedes progression of endothelial dysfunction in sickle mice. Remarkably, D3T reversed the progressive increase in plasma SVCAM-1 levels that we had seen in earlier experiments in the longitudinal cohort, while the DMSO vehicle did not $(P<0.001)$ (Figure 4, A and B). Doubling of the concentration of soluble VE-cadherin (sVE-cadherin) in the plasma of vehicle-treated animals provided additional confirmation of the progressive injury to the endothelium in $\operatorname{SCD}(P<0.001)$ (Figure 4C). D3T stabilized the plasma concentration of VE-cadherin over the course of 3 months, suggesting that the endothelial barrier of the animals in this group was potentially less leaky. Given our earlier results that lung injury was severe at 6 months (Figure 2), we continued D3T treatment in a subgroup of SS mice for an additional 2 months and assessed the effect of the drug on the lung thereafter. Gravimetric analysis of the lungs for edema revealed a significantly lower lung wet/dry weight ratio in the D3T treated SS mice compared with vehicle (Figure 4D). The latter result was confirmed by histology, which also revealed a less congested pulmonary vasculature and lower overall cumulative injury in the lungs of the D3T-treated mice (Figure 4, E and F). Together, these data indicate that activation of $\mathrm{Nrf2}$ can mitigate the vascular endothelial barrier disruption seen in adult SS mice. These results also suggested D3T had a potent effect on the pulmonary endothelium. In agreement with this assessment, Nrf2 nuclear translocation was more robust and stable over 24 hours in lung endothelial cells, while it was relatively transient in erythroid K562 cells treated with D3T (Supplemental Figure 6A). Quantitative PCR (qPCR) analyses of multiple Nrf2 target genes confirmed the enhanced responsiveness of the endothelial cells to D3T (Supplemental Figure 6, B-D).

Targeted deficiency of Nrf2 in nonhematopoietic tissues paradoxically exacerbates anemia in sickle mice. Since Nrf2 activation retarded age-related progression of intravascular hemolysis, vascular inflammation, and pulmonary damage, we reasoned that a deficiency of the transcription factor would accelerate these events in SCD. To test this hypothesis without the confounding effects of a supra-oxidative stress in erythrocytes, which would be caused by completely disrupting Nrf2 activity in sickle erythrocytes, we created BM chi- 
A

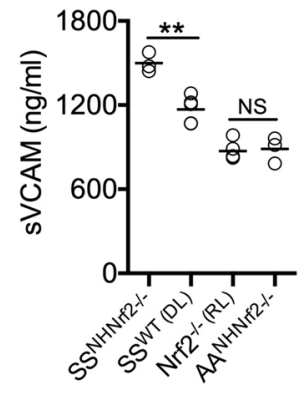

B

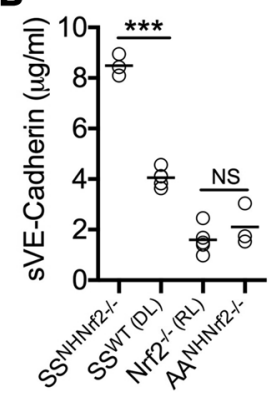

C

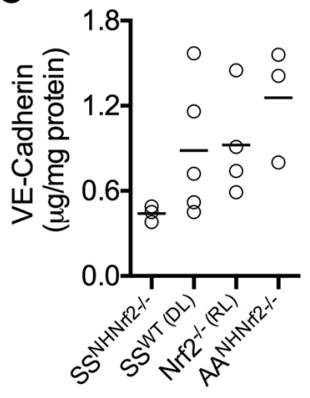

Figure 6. Nrf2 deficiency in nonhematopoietic tissues exacerbates vascular endothelial inflammation in sickle

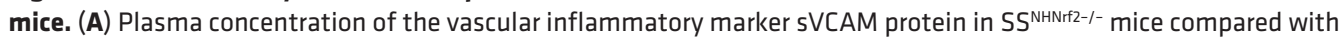
various control mice $(n=3-5)$. (B) Concentration of sVE-cadherin protein in the plasma determined by ELISA $(n=3-5)$. (C) Concentration of VE-cadherin protein in lung homogenates $(n=3-5)$. Note the inverse relationship between the concentrations of the soluble form of VE-cadherin in the plasma and membrane-bound form in the lungs. ${ }^{*} P<0.05$,

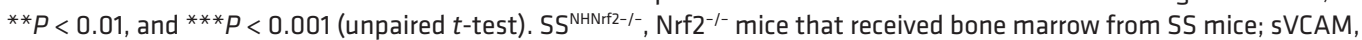
soluble vascular cell adhesion molecule; Nrf2, nuclear factor erythroid-2- related factor 2; sVE-cadherin, soluble vascular endothelial cadherin.

meric SS mice lacking Nrf2 expression exclusively in nonhematopoietic tissues. Successful engraftment and acquisition of SCD was confirmed from the analysis of $\mathrm{Hb}$ by gel electrophoresis (data not shown). In addition, complete blood cell and reticulocyte counts revealed classical hematological features of SCD in the recipient $\mathrm{Nrf}^{-/-}$and congenic C57BL/6J mice that received the SS BM, while the AA BM recipients showed features typical of the AA mouse (Supplemental Table 1). Two of the SS mice lacking nonhematopoietic Nrf2 (referred herein as $\mathrm{SS}^{\mathrm{NHNr2-/-}}$ ) died approximately 3 months after confirmation of SCD, and an additional two died 1 month later. Meanwhile, the congenic $\mathrm{Nrf}^{+/+}$mice that received the SS BM (referred to herein as $\left.\mathrm{SS}^{\mathrm{Nr} 2+/+(\mathrm{B} 6)} ; n=5\right)$, littermates of the SS donor animals (referred to herein as $\mathrm{SS}^{\mathrm{WT}(\mathrm{DL})}, n=5$ ), the $\mathrm{Nrf2}^{-/-}$mice that received the AA BM (now lacking nonhematopoietic Nrf2 and referred herein as $\left.\mathrm{AA}^{\mathrm{NHNr2-/-}}, n=5\right)$, and the $\mathrm{Nrf}^{-/-}$recipient littermates (referred to herein as $\mathrm{Nrf}^{-/(\mathrm{RL})}, n=5$ ) all survived (Figure 5A). Thus, after only 4 months of experiencing SCD the $\mathrm{SS}^{\mathrm{NHNr2-/-}}$ mice had a lethality rate that was approximately 3-fold higher than what was observed in our longitudinal cohort of the naturally born SS mice, which had nonhematopoietic Nrf2 activity intact. These results suggest that a decreased antioxidant gene expression in nonhematopoietic tissues may be a bad prognostic factor in SCD.

The SS $\mathrm{NHNrf2-/}$ mice had significantly higher concentrations of plasma Hb, heme (TPH), and LDH than the congenic and age-matched SS ${ }^{\mathrm{Nr} r+/+(\mathrm{B} 6)}$ (Figure 5, B-D). However, even more remarkably, the concentration of these intravascular hemolysis markers was higher in the $\mathrm{SS}^{\mathrm{NHNr2-/}}$ mice than in the SS ${ }^{\mathrm{WT}(\mathrm{DL})}$ mice that had been exposed to SCD for at least 2 months longer. We interpreted these results to mean that the absence of Nrf2 in nonhematopoietic tissues had accelerated the progression of intravascular hemolysis in the $\mathrm{SS}^{\mathrm{NHNr2-1-}}$ mice. In agreement with this assessment, the plasma hemopexin and haptoglobin levels were comparable, despite the 2-month gap in disease exposure in the SS NHNr2-/- $^{-}$and SS ${ }^{\mathrm{WT}(\mathrm{DL})}$ mice (Supplemental Figure 7, A and B). Moreover, whole blood co-oximetry showed a higher percent of metHb in the $\mathrm{SS}^{\mathrm{NHNr} 2-1-}$ than in the SS${ }^{\mathrm{WT}(\mathrm{DL})}$ mice, indicative of a higher burden of peripheral oxidative stress in the former (Supplemental Figure 8A). Finally, compared with the SSWT(DL) mice, the SS ${ }^{\mathrm{NHNr} r 2-/}$ mice had more oxidized CyS/CySS and GSH/GSSG redox potentials (Supplemental Figure 8, B and C). Together, these results suggest that a decreased antioxidant gene expression in nonhematopoietic tissues intensifies intravascular hemolysis and the oxidant stress in both erythrocytes and in the plasma in SCD.

Nrf2 deficiency in nonhematopoietic tissues causes premature pulmonary edema in sickle mice. We reasoned that the more intense peripheral hemolytic and oxidative stress in the $\mathrm{SS}^{\mathrm{NHNr} 2-/-}$ mice will exacerbate damage to the endothelium in these mice and potentially release more components of the vessel wall into the plasma than in the SS ${ }^{\mathrm{WT}(\mathrm{DL})}$ mice. The concentration of sVCAM in the plasma of the $\mathrm{SS}^{\mathrm{NHNr2-/}}$ mice was significantly higher than in the SS ${ }^{\mathrm{WT}(\mathrm{DL})}$ mice (Figure $6 \mathrm{~A}$ ). Compared with the $\mathrm{SS}^{\mathrm{WT}(\mathrm{DL})}$ mice, the $\mathrm{SS}^{\mathrm{NHNr2-/-}}$ mice had 2-fold higher sVE-cadherin in their plasma (Figure 6B). The lung is sensitive to disruption of the VEcadherin complex with ensuing edema formation (30), which reduces oxygen saturation $\left(\mathrm{SpO}_{2}\right)$. We confirmed that Nrf2 expression was absent in the lungs of the various Nrf2 mutants, including the $\mathrm{SS}^{\mathrm{NHNr2-1}-}$ 
A

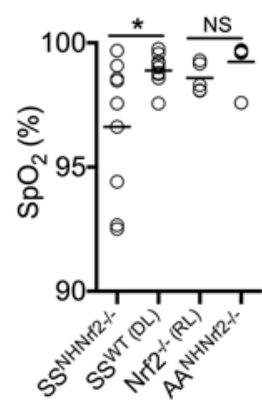

B

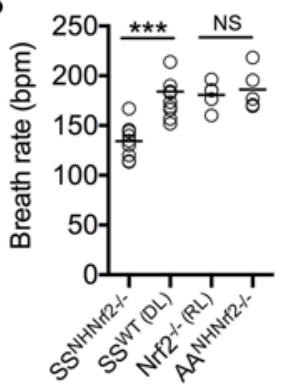

C

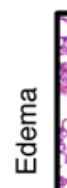
$\mathrm{SS}^{\mathrm{NHN}+2-1-}$ $\mathrm{SS}^{\mathrm{WT}(\mathrm{DL})}$
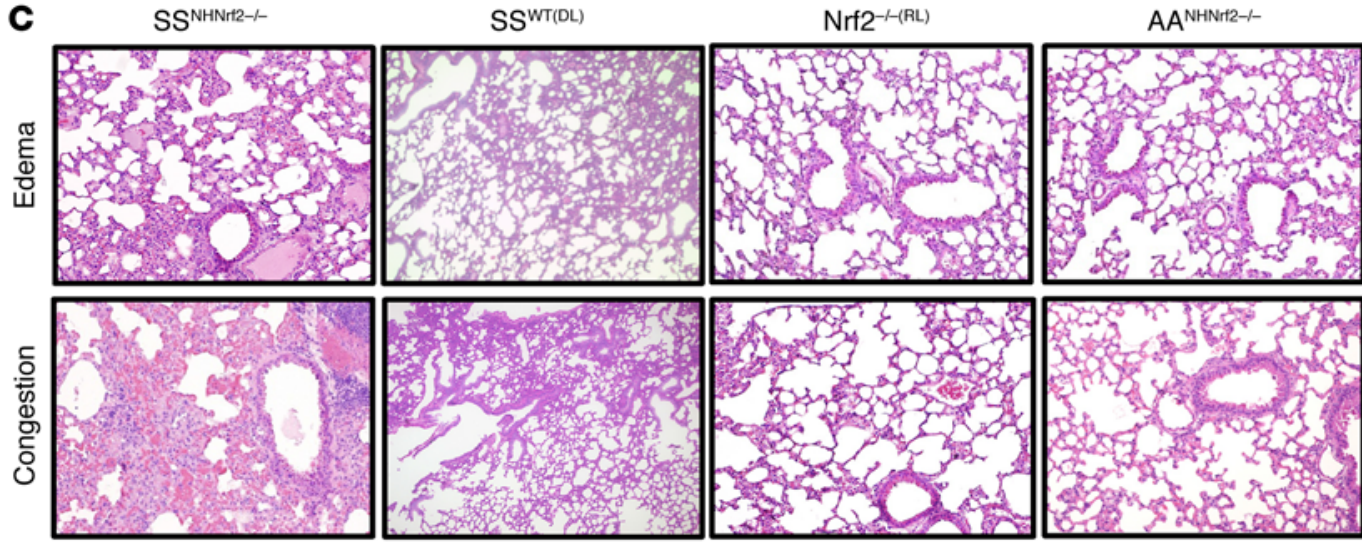
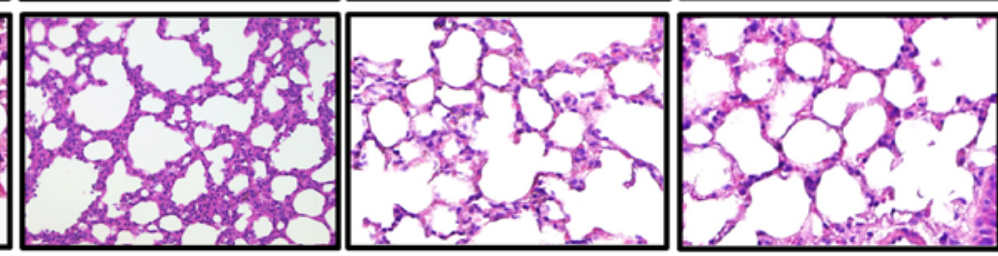

D

E

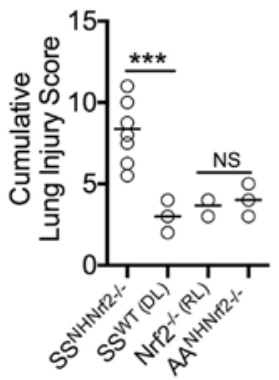

Figure 7. Nrf2 deficiency in nonhematopoietic tissues causes premature lung edema in sickle mice. (A) Oxygen saturation (\% $\left.\mathrm{SpO}_{2}\right)$ and $(\mathbf{B})$ breath rate,

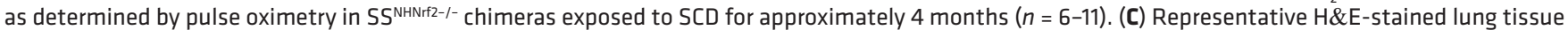
sections. Original magnification, $\times 100$ (edema and congestion); $\times 400$ (Alveolar [Alv.] wall thickening). (D) Semiquantitative cumulative lung injury score derived from edema, congestion, and alveolar wall thickness in lung tissue sections $(n=3-9)$. (E) Gravimetric assessment of lung edema ( $n=6)$. Statistical analysis was performed using unpaired $t$ test. ${ }^{*} P<0.05$, ${ }^{*} P<0.01$, and ${ }^{* * *} P<0.001$. Nrf2, nuclear factor erythroid-2- related factor 2 ; SS ${ }^{\mathrm{NHN}} \mathrm{rz2--}$, Nrf2 ${ }^{-/-}$ mice that received bone marrow from SS mice; SS ${ }^{\mathrm{WT}(\mathrm{DL})}$, littermates of the SS mice that were used as BM donors; Nrf2 ${ }^{-1-(\mathrm{RL})}$, littermates of Nrf2 ${ }^{-1-}$ mice that received SS or AA BM; $\mathrm{AA}^{\mathrm{NHNr}+2-/-}$, $\mathrm{Nrf2}^{-/-}$mice that were transplanted with $\mathrm{AA} B M$; SCD, sickle cell disease.

mice (Supplemental Figure 9). The VE-cadherin protein concentration in lung homogenates determined by ELISA was lower in the $\mathrm{SS}^{\mathrm{NHNr} r 2-/-}$ mice, consistent with the substantially elevated concentration of the adhesion molecule in the plasma of the same animals (Figure 6C). Previous studies have shown that $\mathrm{SpO}_{2}$ in nonanesthetized transgenic SS mice is normal at steady state $(31,32)$, and we confirmed this finding in the $\mathrm{SS}^{\mathrm{WT}(\mathrm{DL})}$ mice in this study (Figure 7A). The $\mathrm{SpO}_{2}$ in $\mathrm{SS}^{\mathrm{NHNr2-/-}}$ mice was significantly reduced indicative of oxygen desaturation - coupled to a low breath rate, which suggested that these mice had developed a severe respiratory disease (Figure 7, A and B). The presence of multifocal alveolar edema, alveolar wall thickening, and vascular congestion in lung sections confirmed a severe lung disease in the $\mathrm{SS}^{\mathrm{NHNr} r 2--}$ mice after only approximately 4 months of SCD (Figure 7, C and D). Higher lung wet/dry weight ratio identified increased endothelial permeability in the pathogenesis of the respiratory disease in the $\mathrm{SS}^{\mathrm{NHNr2}-/-}$ mice (Figure 7E). Collectively, these results provide physiologic, pathologic, and biological evidence of premature pulmonary edema in SS mice with deficiency of Nrf2 in nonhematopoietic tissues, including in the lungs.

\section{Discussion}

We have identified an association between worsening intravascular hemolysis and the rapid clinical deterioration seen during adult transition in SCD. In addition, we provide genetic and pharmacological evidence 
demonstrating that targeting Nrf2 prophylactically can impede and potentially reverse these interrelated events. First, we discovered a blunted developmental increase and progressive decline in plasma hemopexin in SS mice, which inevitably heightened the deleterious effects of extracellular heme with aging. Second, pharmacological activation of Nrf2 stabilized intravascular hemolysis, reversed deterioration of vascular inflammation, and protected adult SS mice from inevitable lung damage due in part to reduced endothelial leakage. Third, we discovered that loss of Nrf2 in nonhematopoietic tissues not only impacted disease progression in nonhematopoietic tissues such as the lungs, but also influenced intravascular hemolysis. Collectively, these results allow us to conclude that Nrf2 activity in nonhematopoietic tissues exerts a dominant protective role against the progression of the severe adult-phenotype of SCD.

The poor outcome in young adult SCD patients is currently attributed largely to deficiencies in health care services, limited number of providers skilled in adult SCD care $(33,34)$, the inability of adult patients to effectively navigate health care systems and their lack of self-efficacy in disease management, and the generally poor access to health care among African-Americans (35-37). While transition programs appear to help some patients overcome these systemic problems $(37,38)$, there is a paucity of data on the role the pathobiology of SCD plays in the adult transition. We obtained longitudinal results on several interrelated disease markers in SS mice for the first time, which helps to explain, mechanistically, the rapid deterioration of SCD during the adult transition. In agreement with observations in humans, the SS mice in this study presented with a more severe disease phenotype at the adult stage beginning at 3 months, clearly free from the deficiencies in health care services that influence the disease in humans. Key intravascular hemolysis markers, notably LDH and TPH, and vascular endothelial injury markers sVCAM-1 and sVE-cadherin increased significantly at 3 months, which is a comparable age to humans at 20 years. The anemia deteriorated markedly at 6 months, which is strikingly comparable to the 30-year age when SCD patients also experience a significant drop in total $\mathrm{Hb}$ (39). In addition, nearly all deaths in the longitudinal cohort of SS mice occurred after 3 months, which is comparable to the stage of maturation of young adult humans (ref. 26 and Figure 1A). These results provided important validation of the experimental approach, and the Townes SS mouse model used in this longitudinal cohort study.

Hemopexin was at its lowest level at 1 month in both SS and control mice, suggesting that the expression of this molecule may be developmentally regulated in mammals similarly to the pattern of expression in chicks (40). To test this idea, we performed a secondary analysis of data from our previous study of children with SCD (41), which revealed a correlation between age and plasma hemopexin level $(r=0.25$, $P=0.02)$. The median value of hemopexin was 2 -fold lower in children $<10$ years old $(n=43)$ compared with those $>10$ years $(n=39)$. Further studies that include adult and neonates are needed to confirm the developmental expression of hemopexin in humans. Intriguingly, plasma heme was lowest also at 1 month in the SS mice, despite the exceedingly low level of hemopexin. We postulate that a hemopexin-independent mechanism is involved in controlling plasma heme levels in early development. Plasma HO-1 may play this role because of the significantly higher levels we found in the 1-month compared with the 2-month SS mice in this study. This idea is enhanced by the results of our study that are focused on acute chest syndrome, showing that the HO-1 in plasma possesses enzymatic activity (data not shown). Interestingly, HO-1 expression is downregulated in 1-month-old SS mice administered hemopexin (42), consistent with the notion that the expression of these 2 molecules may be diametrically regulated in SCD, at least during early development. In the current study, D3T stabilized intravascular hemolysis and reversed vascular inflammation without raising plasma hemopexin levels in individual SS mice (data not shown). While hemopexin replacement therapy is unlikely to stabilize intravascular hemolysis, it may slow the progression in vascular inflammation seen in adult mice, particularly in combination therapy with Nrf2 activation. Increased plasma ferritin in the D3T-treated mice can be explained by both a direct effect involving Nrf2 activation and an indirect effect involving stabilization of HO-1 and the subsequent release of iron to stimulate ferritin production.

One of the most fascinating findings of this study is that Nrf2 disruption in nonhematopoietic tissues exacerbated intravascular hemolysis in the SS mice (Figure 5). This result suggests that oxidative stress in nonerythroid tissues, such as the vessel wall, contributes to the intravascular hemolysis phenotype in SCD, as well as the previously reported hemolytic anemia in the Nrf2-null mouse (19). Nrf2 activity is controlled primarily by Kelch-like EHC-associated protein 1 (Keap1), a substrate adaptor protein of Cullin-3-based (Cul3-based) ubiquitin E3 ligase. The Keap1-Cul3 complex ubiquitinates Nrf2 for degradation in the proteasome pathway. Inactivation of Keap1 by oxidative stress or xenobiotic stress releases Nrf2 for nuclear 
translocation where it heterodimerizes with small Maf proteins and binds to ARE elements to alter gene expression. Interestingly, the constitutive activation of Nrf2 via the combination of hypomorphic floxed and null alleles for Keap1 does not improve intravascular hemolysis in SS mice (43). There are alternative Keap1-independent mechanisms that regulate Nrf2 activity $(44,45)$, such as phosphorylation of Nrf2 by multiple protein kinases (46-49) and interaction with other partner proteins $(50,51)$. We postulate that Nrf2 activation via these alternate mechanisms may promote a paracrine antioxidant effect to ameliorate oxidative damage to sickle erythrocytes and ultimately to impede progression of SCD. A recent study showed that approximately $30 \%$ of free heme in the plasma of SCD patients is housed in erythrocyte membrane microparticles, which can be transferred to endothelial cells in vitro to cause injury (52). Endothelium may therefore posses a counteractive antioxidant effect to mitigate the danger posed by sickle erythrocytes and, perhaps more specifically, heme-ladden membrane microparticles. Additional studies will be required to further explore this idea and to identify the role of endothelial HO-1 and other Nrf2 target genes that may be involved in this defense mechanism.

A potential limitation of this study is that irradiation damage to the BM during transplantation and graft versus host disease contributed to the severe disease phenotype of the $\mathrm{SS}^{\mathrm{NHNr} r 2-/}$ mice. However, there are several evidentiary examples that mitigate these concerns. The $\mathrm{Nrf}^{-/-}$mice are on the same genetic background as the congenic $\mathrm{Nrf2}^{+/+}$mice, and both animals received the same pool of BM from SS donor mice. Total $\mathrm{Hb}$ was slightly higher in the $\mathrm{SS}^{\mathrm{NHNr2-/-}}$ chimeras than in the radiation-free $\mathrm{SS}{ }^{\mathrm{WT}(\mathrm{DL})}$ mice, which argues against radiation damage to the BM. Congenic chimeric SS $\mathrm{SLR}^{\mathrm{TL} /-}$ mice generated in a previous study using the same transplant protocol used in this study are resistant to a lethal acute lung injury that develops readily in $\mathrm{SS}^{\mathrm{WT}(\mathrm{DL})}$ mice (31). We did not observe any of the typical features of graft versus host disease in the lungs such as fibrosis and leukocyte infiltration in the SS $\mathrm{NHNr2-/-}^{-}$chimeras. Finally, we obtained compelling, diametrically opposed data from our gain-of-function experiment with D3T in WT SS mice that support the data derived from the $\mathrm{SS}^{\mathrm{NHNr} r 2-/-}$ mice. Thus, it is reasonable to conclude that the interrelated phenotypes of severe intravascular hemolysis, exaggerated peripheral oxidative stress, and worsened vascular endothelial dysfunction seen in the $\mathrm{SS}^{\mathrm{NHNr} r 2--}$ mice reflects the major role played by the antioxidant defense system in the nonhematopoietic compartment, most notably the vessel wall, in SCD.

Respiratory pathology is a leading cause of death in adult SCD patients (2). In the largest autopsy study of SCD to date, spanning nearly a century in 1889-1981, pulmonary edema was identified as the most frequent lung pathology (53). This finding has been replicated in a recent study in 1990-2004 at Grady Memorial Hospital (Atlanta, Georgia, USA; ref. 54), reaffirming the role of endothelial barrier dysfunction in the pathobiology of SCD. The adherens junction complex and its major adhesive constituent VE-cadherin is the central component of the endothelial barrier. Disruption of the adherens junction complex is linked to raised VE-cadherin in the plasma of patients with acute respiratory distress syndrome (55). Data from the current study indicate that prophylactic therapy using Nrf2 activators can mitigate disruption of the adherens junction and impede progression of tissue edema in the lungs. However, there are potential risks with Nrf2 activator therapy, including cardiovascular events, which led to early termination of the trial with bardoxolone methyl (methyl 2-cyano-3,12-dioxooleana-1,9-dien-28-oate; CDDO-me) in chronic kidney disease and type 2 diabetes mellitus (56). A precision medicine approach focused on targeting the endothelium may help to mitigate potential off-target effects. Our preliminary studies show that CDDO-me also causes robust activation of Nrf2 in endothelial cells. Thus the effects reported here for D3T may be replicated with other Nrf2 activators to impede disease progression in SCD.

In summary, we have identified a Nrf2-mediated defense in nonhematopoietic tissues as a major mitigating factor in intravascular hemolysis, oxidative stress, vascular inflammation, pulmonary vascular leakage, and respiratory disease in SCD. These findings provide a strong rationale to develop drugs that can activate Nrf2, preferentially in endothelium, to slow progression of the severe adult phenotype of SCD.

\section{Methods}

Mice. Male and female SS mice and strain controls expressing normal human $\mathrm{Hb}$ (AA mice) were used (57). Nrf2 KO (Nrf2-/-) mice were obtained from the Jackson Laboratory (stock \#017009; B6.129X1-Nfe2l2$t m 1 Y w k / J)$. Mouse genotypes were confirmed by PCR. For treatment with D3T (Sigma-Aldrich, \#D5571), 1-month-old sickle mice received oral gavage of vehicle (DMSO) or D3T $(0.5 \mathrm{mmol} / \mathrm{kg} \mathrm{BW}) 3 \times$ per week for 3-5 months. Mice were phlebotomized by retro-orbital bleeding using a capillary tube internally coated with heparin/EDTA anticoagulant. 
Cells. Primary human microvascular endothelial cells (HMVEC; Lonza, \#CC2527) were seeded at a density of $25 \times 10^{4}$ cells per well in 6-well plates 72 hours prior to drug treatment. Once the cells reached confluency, they were treated either with $50 \mu \mathrm{M}$ D3T or vehicle (DMSO) for 12 and 24 hours. K562 (ATCC, \#CCL-243) suspension cells were seeded to achieve a final density of $6 \times 10^{6}$ cells per well in 6-well plates and treated either with $50 \mu \mathrm{M}$ D3T or vehicle (DMSO) for 12 and 24 hours.

Real-time PCR analysis. Total RNA was extracted from HMVEC or K562 cells using RNeasy mini-kits (QIAGEN, \#74106) according to the manufacturer's protocol. Nanodrop quantification was performed, and $500 \mathrm{ng}$ of total RNA was reverse transcribed using the high-capacity cDNA reverse transcription kit (Invitrogen). Real-time PCR was performed with the Step-one Plus (Applied Biosystems) instrument and Taqman gene expression probes (Invitrogen). Relative quantification was calculated with the standard $\Delta \Delta \mathrm{Ct}$ method; target gene transcripts were normalized to the $18 \mathrm{~S}$ ribosomal transcripts and D3T-treated samples were further normalized to vehicle control gene transcripts to show fold induction.

Nuclear extraction and Western blot. Nuclear fractionation of HMVEC and K562 lysates was performed using the NE-PER nuclear and cytoplasmic extraction reagents (ThermoFisher Scientific). Lysates were concentrated using the Amicon Ultra Centrifugal filters (Millipore) and subsequently quantified using the BCA assay kit (ThermoFisher Scientific, \#23225). For SDS-PAGE electrophoresis, $20 \mu \mathrm{g}$ of total protein was used, and the blots were subsequently probed with nuclear factor, erythroid-like 2 (NRF2; Abcam, \#ab62352) and MutS protein homolog 2 (MSH2; Abcam, \#ab70270) antibodies.

BM transplantation (BMT). $\mathrm{Nrf}^{-1-}$ mice were maintained on acidified drinking water for 7 days and subjected to 2 doses of 600 rads irradiation given 4 hours apart. Irradiated mice (8-10 weeks old) were transplanted with $2 \times 10^{6}$ whole BM cells harvested from similarly aged SS or AA mouse donors. Congenital control C57BL/6J mice (8-10 weeks old), purchased from the Jackson Laboratory (stock \#000664)

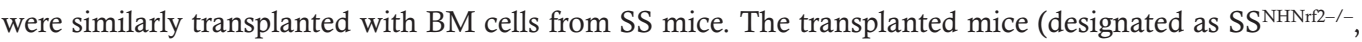
$\mathrm{AA}^{\mathrm{NHNr}-1-}$, and $\mathrm{SS}^{\mathrm{Nr} r 2+/(\mathrm{B} 6)}$ ) were maintained on medicated (Neomycin: $0.5 \mathrm{mg} / \mathrm{ml}$; Polymyxin B: 0.0125 $\mathrm{mg} / \mathrm{ml}$ ) water for 1 week. Nontransplanted age-matched recipient littermates $\mathrm{Nrf}^{-/(\mathrm{RL})}$ and SS donor littermates $\left(\mathrm{SS}^{\mathrm{WT}(\mathrm{DL})}\right)$ were maintained along with the transplanted mice for control analysis. Complete blood count (CBC) was performed using HemaTrue hematology analyzer (Heska), and reticulocyte count was performed using flow cytometry. Transplanted mice were monitored for survival after confirmed engraftment 8 weeks following BMT. The chimeric, donor, and recipient littermates were euthanized to harvest plasma and organs at 4 months following BMT.

Whole blood co-oximetry. Total $\mathrm{Hb}$ concentration and percentage of metHb were measured in venous whole blood using a portable CO-oximeter (AVOXImeter 4000, ITC) as described elsewhere (58). The device measures the level of different $\mathrm{Hb}$ parameters using novel optics and multiple wavelengths (59).

Plasma analysis. Freshly collected EDTA anticoagulated blood samples were centrifuged at 1,200 $\times$ $g$ for 15 minutes to collect plasma. Total plasma $\mathrm{Hb}$ and total heme content (TPH) in the unfractionated plasma was quantified using a colorimetric assay kit (BioAssay Systems, \#DIHM-250 and \#DIHB-250) as described in previous studies $(58,60)$. LDH activity was determined using a colorimetric assay kit from BioAssay Systems (\#D2DH-100). ELISA with specific commercial kits (Kamiya Biomedical Company) was used to measure the concentration of hemopexin (\#KT-345) and haptoglobin (\#KT-189) following instructions provided by vendor. sVCAM was quantified using quantikine ELISA kits from R\&D Systems (\#MVC00) following manufacturer's instructions. Plasma level of VE-cadherin was determined using a specific soluble VE-cadherin ELISA kit from Cusabio Inc. (\#CSB-EL005054MO). Concentration of HO-1 in the plasma and in lung homogenate was measured using ELISA kit from Enzo Life Sciences (\#ADI960-071) following manufacturer's instruction.

Measurement of GSH/GSSG and Cys/CySS redox potential in plasma. Plasma redox states were measured as described previously (61). In brief, $50 \mu \mathrm{l}$ of blood was placed in a solution containing L-serine, heparin, bathophenanthroline disulfonate (BPDS), and iodoacetic acid in borate buffer. Samples were centrifuged immediately, and supernatants were collected and placed in an equal volume of $10 \%$ perchloric acid and kept at $-20^{\circ} \mathrm{C}$. Samples were derivatized, and GSH, GSSG, Cys, and CySS were measured by HPLC as $S$-carboxymethyl $N$-dansyl derivatives using $\gamma$-glutamylglutamate as an internal standard. Redox potential $\left(\mathrm{E}_{\mathrm{h}}\right)$ values were calculated using the Nernst equation for the respective GSH/GSSG and Cys/CySS pools: $\mathrm{E}_{\mathrm{h}}=-264+30 \log \left([\mathrm{GSSG}] /[\mathrm{GSH}]^{2}\right)$ for $\mathrm{pH} 7.4$ and $\mathrm{E}_{\mathrm{h}}=-250+30 \log \left[(\mathrm{CySS}) /(\mathrm{Cys})^{2}\right]$ for $\mathrm{pH} 7.4$.

Pulse-oximetry. The MouseOx pulse-oximeter (Starr Life Sciences) was used (62) to measure real-time oxygen saturation (percent $\mathrm{SpO}_{2}$; percentage of functional arterial $\mathrm{Hb}$ ) and breath rate (breath rate per 
minute) in awake conditions. Hairs from the collar region (back of the neck) of the mice were removed by using a depilatory agent a day before actual measurement. A disposable sensory collar clip attached to the pulse-oximeter was placed on the hairless area, and measurements were initiated through MouseOx software (version 6.3; provided by the manufacturer) when data displays were without error codes.

Gravimetric analysis of lung edema. Lungs were weighed immediately after harvest using an isometric transducer (Harvard Apparatus) and were then dried in an oven at $80^{\circ} \mathrm{C}$ containing desiccant crystals for 24 hours, dry weight determined, and ratios calculated (63).

Histopathology. Lungs were uniformly fixed immediately after harvest in 10\% buffered formalin. Sections $(5 \mu \mathrm{m})$ of formalin-fixed paraffin embedded tissues (FFPE tissues) were deparaffinized, rehydrated, and stained with H\&E and examined using Olympus AX70 microscope. Images were recorded with an Olympus U-CMAD3 DP70 camera and OlympusDP70/DP30 BW (ver. 02.0201.147) software. Histopathological analysis was performed using a scoring system based on the following criteria: edema, alveolar wall thickening, and vascular congestion. Sections were graded by assigning the following scores; absent $=0$, mild $=1$, moderate $=2$, severe $=3$, and very severe $=4$. Individual scores were tabulated from the mean score from 6 random focal areas (magnification: $\times 100$ ) to obtain an overall score ranging from $0-12$. The mean injury score was determined for lungs from each animal in an experimental group $(n=3-5)$ to generate a cumulative lung injury score.

Statistics. Results are reported as mean \pm SEM. To analyze statistical significance, 2-tailed paired or unpaired Student's $t$ test and 1-way ANOVA were used as appropriate. GraphPad Prism 6 software was used for all statistical analyses. $P$ values less than 0.05 were considered significant.

Study approval. The Institutional Animal Care and Use Committees at the University of Pittsburgh (Protocol \#13102569) and Emory University (DAR-118-2010-070813) approved the studies on mice.

\section{Author contributions}

SFOA designed the study. SG, CAI, RH, ALW, JMH, and DRA designed and performed the experiments. SG, ATOA, and SFOA wrote the manuscript.

\section{Acknowledgments}

This study was conducted with research funding from the National Heart, Lung and Blood Institute (NHLBI) (Award Number: R01 HL106192 and U01 HL117721). We thank Frances Weidert, Bethany Flage, and Prasanthi Chappa for their technical support. We thank Sonia Mckoy for carefully proofreading this manuscript.

Address correspondence to: Solomon F. Ofori-Acquah, 200 Lothrop Street, Pittsburgh, Pennsylvania 15261, USA. Phone: 412.648.9231; E-mail: sfo2@pitt.edu.

1. Platt OS, et al. Mortality in sickle cell disease. Life expectancy and risk factors for early death. $N$ Engl J Med. 1994;330(23):1639-1644.

2. Hamideh D, Alvarez O. Sickle cell disease related mortality in the United States (1999-2009). Pediatr Blood Cancer. 2013;60(9):1482-1486

3. Quinn CT, Rogers ZR, McCavit TL, Buchanan GR. Improved survival of children and adolescents with sickle cell disease. Blood. 2010;115(17):3447-3452.

4. Telfer P, et al. Clinical outcomes in children with sickle cell disease living in England: a neonatal cohort in East London. Haematologica. 2007;92(7):905-912

5. Quinn CT, Rogers ZR, Buchanan GR. Survival of children with sickle cell disease. Blood. 2004;103(11):4023-4027.

6. Gaston $\mathrm{MH}$, et al. Prophylaxis with oral penicillin in children with sickle cell anemia. A randomized trial. NEngl J Med. 1986;314(25):1593-1599.

7. Lanzkron S, Carroll CP, Haywood C Jr. Mortality rates and age at death from sickle cell disease: U.S., 1979-2005. Public Health Rep. 2013;128(2):110-116.

8. Yanni E, Grosse SD, Yang Q, Olney RS. Trends in pediatric sickle cell disease-related mortality in the United States, 19832002. J Pediatr. 2009;154(4):541-545

9. Grosse SD, Odame I, Atrash HK, Amendah DD, Piel FB, Williams TN. Sickle cell disease in Africa: a neglected cause of early childhood mortality. Am J Prev Med. 2011;41(6 suppl 4):S398-S405.

10. Piel FB, Hay SI, Gupta S, Weatherall DJ, Williams TN. Global burden of sickle cell anaemia in children under five, 2010-2050: modelling based on demographics, excess mortality, and interventions. PLoS Med. 2013;10(7):e1001484.

11. Fleming AF. The presentation, management and prevention of crisis in sickle cell disease in Africa. Blood Rev. 1989;3(1):18-28.

12. Wierenga KJJ, Hambleton IR, Lewis NA, Unit SC. Survival estimates for patients with homozygous sickle-cell disease in 
Jamaica: a clinic-based population study. Lancet. 2001;357(9257):680-683.

13. de Montalembert M, Guitton C. Transition from paediatric to adult care for patients with sickle cell disease. $\mathrm{Br} J \mathrm{Haematol}$. 2014;164(5):630-635.

14. Nouraie $\mathrm{M}$, et al. The relationship between the severity of hemolysis, clinical manifestations and risk of death in 415 patients with sickle cell anemia in the US and Europe. Haematologica. 2013;98(3):464-472.

15. Muller-Eberhard U, Javid J, Liem HH, Hanstein A, Hanna M. Plasma concentrations of hemopexin, haptoglobin and heme in patients with various hemolytic diseases. Blood. 1968;32(5):811-815.

16. Gladwin MT, Ofori-Acquah SF. Erythroid DAMPs drive inflammation in SCD. Blood. 2014;123(24):3689-3690

17. Lee JM, et al. Nrf2, a multi-organ protector? FASEB J. 2005;19(9):1061-1066.

18. Thimmulappa RK, et al. Nrf2-dependent protection from LPS induced inflammatory response and mortality by CDDOImidazolide. Biochem Biophys Res Commun. 2006;351(4):883-889.

19. Lee JM, Chan K, Kan YW, Johnson JA. Targeted disruption of Nrf2 causes regenerative immune-mediated hemolytic anemia. Proc Natl Acad Sci U S A. 2004;101(26):9751-9756.

20. Neumann CA, et al. Essential role for the peroxiredoxin Prdx1 in erythrocyte antioxidant defence and tumour suppression. Nature. 2003;424(6948):561-565.

21. Schacter L, Warth JA, Gordon EM, Prasad A, Klein BL. Altered amount and activity of superoxide dismutase in sickle cell anemia. FASEB J. 1988;2(3):237-243.

22. Chiu D, Lubin B. Abnormal vitamin E and glutathione peroxidase levels in sickle cell anemia: evidence for increased susceptibility to lipid peroxidation in vivo. J Lab Clin Med. 1979;94(4):542-548.

23. Tatum VL, Chow CK. Antioxidant status and susceptibility of sickle erythrocytes to oxidative and osmotic stress. Free Radic Res. 1996;25(2):133-139.

24. Morris CR, et al. Erythrocyte glutamine depletion, altered redox environment, and pulmonary hypertension in sickle cell disease. Blood. 2008;111(1):402-410.

25. Sangokoya C, Telen MJ, Chi JT. microRNA miR-144 modulates oxidative stress tolerance and associates with anemia severity in sickle cell disease. Blood. 2010;116(20):4338-4348.

26. Flurkey K, Currer JM, Harrison DE. The mouse in aging research. In: Fox JG, Barthold SW, Davisson MT, Newcomer CE, Quimby FW, Smith AL, eds. The Mouse in Biomedical Research. Vol 3. 2nd ed. Burlington, Massachusetts, USA: Elsevier Academic Press; 2007:637-672.

27. Hansen JM, Zhang H, Jones DP. Differential oxidation of thioredoxin-1, thioredoxin-2, and glutathione by metal ions. Free Radic Biol Med. 2006;40(1):138-145.

28. Kato GJ, et al. Levels of soluble endothelium-derived adhesion molecules in patients with sickle cell disease are associated with pulmonary hypertension, organ dysfunction, and mortality. Br J Haematol. 2005;130(6):943-953.

29. Kwak MK, Wakabayashi N, Itoh K, Motohashi H, Yamamoto M, Kensler TW. Modulation of gene expression by cancer chemopreventive dithiolethiones through the Keap1-Nrf2 pathway. Identification of novel gene clusters for cell survival. $J$ Biol Chem. 2003;278(10):8135-8145.

30. Corada M, et al. Vascular endothelial-cadherin is an important determinant of microvascular integrity in vivo. Proc Natl Acad Sci US A. 1999;96(17):9815-9820.

31. Ghosh S, et al. Extracellular hemin crisis triggers acute chest syndrome in sickle mice. J Clin Invest. 2013;123(11):4809-4820.

32. Kaul DK, Fabry ME, Suzuka SM, Zhang X. Antisickling fetal hemoglobin reduces hypoxia-inducible factor-1 $\alpha$ expression in normoxic sickle mice: microvascular implications. Am J Physiol Heart Circ Physiol. 2013;304(1):H42-H50.

33. Okumura MJ, Heisler M, Davis MM, Cabana MD, Demonner S, Kerr EA. Comfort of general internists and general pediatricians in providing care for young adults with chronic illnesses of childhood. J Gen Intern Med. 2008;23(10):1621-1627.

34. Treadwell M, Telfair J, Gibson RW, Johnson S, Osunkwo I. Transition from pediatric to adult care in sickle cell disease: establishing evidence-based practice and directions for research. Am J Hematol. 2011;86(1):116-120.

35. Clark LT. Issues in minority health: atherosclerosis and coronary heart disease in African Americans. Med Clin North Am. 2005;89(5):977-1001.

36. Brousseau DC, Owens PL, Mosso AL, Panepinto JA, Steiner CA. Acute care utilization and rehospitalizations for sickle cell disease. JAMA. 2010;303(13):1288-1294.

37. Jordan L, Swerdlow P, Coates TD. Systematic review of transition from adolescent to adult care in patients with sickle cell disease. J Pediatr Hematol Oncol. 2013;35(3):165-169.

38. Andemariam B, Owarish-Gross J, Grady J, Boruchov D, Thrall RS, Hagstrom JN. Identification of risk factors for an unsuccessful transition from pediatric to adult sickle cell disease care. Pediatr Blood Cancer. 2014;61(4):697-701.

39. Hayes RJ, Beckford M, Grandison Y, Mason K, Serjeant BE, Serjeant GR. The haematology of steady state homozygous sickle cell disease: frequency distributions, variation with age and sex, longitudinal observations. Br J Haematol. 1985;59(2):369-382.

40. Grieninger G, Liang TJ, Beuving G, Goldfarb V, Metcalfe SA, Muller-Eberhard U. Hemopexin is a developmentally regulated, acute-phase plasma protein in the chicken. J Biol Chem. 1986;261(33):15719-15724.

41. Adisa OA, Hu Y, Ghosh S, Aryee D, Osunkwo I, Ofori-Acquah SF. Association between plasma free haem incidence of vaso-occlusive episodes acute chest syndrome in children with sickle cell disease. Br J Haematol. 2013;162(5):702-705.

42. Vinchi F, et al. Hemopexin therapy improves cardiovascular function by preventing heme-induced endothelial toxicity in mouse models of hemolytic diseases. Circulation. 2013;127(12):1317-1329.

43. Keleku-Lukwete N, et al. Amelioration of inflammation and tissue damage in sickle cell model mice by Nrf2 activation. Proc Natl Acad Sci U S A. 2015;112(39):12169-12174.

44. Rojo AI, et al. Signaling pathways activated by the phytochemical nordihydroguaiaretic acid contribute to a Keap1-independent regulation of Nrf2 stability: Role of glycogen synthase kinase-3. Free Radic Biol Med. 2012;52(2):473-487.

45. Bryan HK, Olayanju A, Goldring CE, Park BK. The Nrf2 cell defence pathway: Keap1-dependent and -independent mechanisms of regulation. Biochem Pharmacol. 2013;85(6):705-717.

46. Numazawa S, Ishikawa M, Yoshida A, Tanaka S, Yoshida T. Atypical protein kinase C mediates activation of NF-E2-related factor 2 in response to oxidative stress. Am J Physiol Cell Physiol. 2003;285(2):C334-C342. 
47. Jain AK, Jaiswal AK. Phosphorylation of tyrosine 568 controls nuclear export of Nrf2. J Biol Chem. 2006;281(17):12132-12142.

48. Jain AK, Jaiswal AK. GSK-3beta acts upstream of Fyn kinase in regulation of nuclear export and degradation of NF-E2 related factor 2. J Biol Chem. 2007;282(22):16502-16510

49. Yuan X, et al. Butylated hydroxyanisole regulates ARE-mediated gene expression via Nrf2 coupled with ERK and JNK signaling pathway in HepG2 cells. Mol Carcinog. 2006;45(11):841-850.

50. Clements CM, McNally RS, Conti BJ, Mak TW, Ting JP. DJ-1, a cancer- and Parkinson's disease-associated protein, stabilizes the antioxidant transcriptional master regulator Nrf2. Proc Natl Acad Sci U S A. 2006;103(41):15091-15096.

51. Chen W, et al. Direct interaction between Nrf2 and p21(Cip1/WAF1) upregulates the Nrf2-mediated antioxidant response. Mol Cell. 2009;34(6):663-673.

52. Camus SM, et al. Circulating cell membrane microparticles transfer heme to endothelial cells and trigger vasoocclusions in sickle cell disease. Blood. 2015;125(24):3805-3814.

53. Haupt HM, Moore GW, Bauer TW, Hutchins GM. The lung in sickle cell disease. Chest. 1982;81(3):332-337.

54. Graham JK, Mosunjac M, Hanzlick RL, Mosunjac M. Sickle cell lung disease and sudden death: a retrospective/prospective study of 21 autopsy cases and literature review. Am J Forensic Med Pathol. 2007;28(2):168-172.

55. Carden D, Xiao F, Moak C, Willis BH, Robinson-Jackson S, Alexander S. Neutrophil elastase promotes lung microvascular injury and proteolysis of endothelial cadherins. Am J Physiol. 1998;275(2 pt 2):H385-H392.

56. de Zeeuw D, et al. Bardoxolone methyl in type 2 diabetes and stage 4 chronic kidney disease. N Engl J Med. 2013;369(26):2492-2503

57. Wu LC, Sun CW, Ryan TM, Pawlik KM, Ren J, Townes TM. Correction of sickle cell disease by homologous recombination in embryonic stem cells. Blood. 2006;108(4):1183-1188.

58. Pamplona A, et al. Heme oxygenase-1 and carbon monoxide suppress the pathogenesis of experimental cerebral malaria. Nat Med. 2007;13(6):703-710.

59. Hemmi H, et al. The roles of two IкB kinase-related kinases in lipopolysaccharide and double stranded RNA signaling and viral infection. J Exp Med. 2004;199(12):1641-1650.

60. Seixas E, et al. Heme oxygenase-1 affords protection against noncerebral forms of severe malaria. Proc Natl Acad Sci U S A. 2009;106(37):15837-15842.

61. Jones DP, et al. Glutathione measurement in human plasma. Evaluation of sample collection, storage and derivatization conditions for analysis of dansyl derivatives by HPLC. Clin Chim Acta. 1998;275(2):175-184

62. Verhoeven D, Teijaro JR, Farber DL. Pulse-oximetry accurately predicts lung pathology and the immune response during influenza infection. Virology. 2009;390(2):151-156.

63. Ghosh S, Tan F, Ofori-Acquah SF. Spatiotemporal dysfunction of the vascular permeability barrier in transgenic mice with sickle cell disease. Anemia. 2012;2012:582018. 